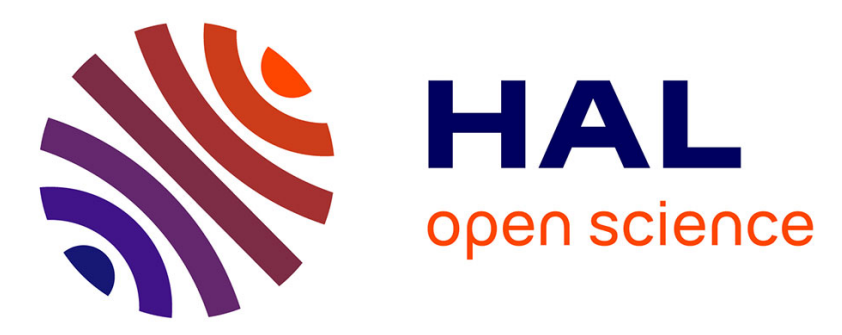

\title{
'That's just the cesspool where they dump all the trash': exploring working class men's perceptions and experiences of social capital and health
}

\author{
Alan Dolan
}

\section{- To cite this version:}

Alan Dolan. 'That's just the cesspool where they dump all the trash': exploring working class men's perceptions and experiences of social capital and health. Health, 2007, 11 (4), pp.475-495. $10.1177 / 1363459307080869$. hal-00571438

\section{HAL Id: hal-00571438 \\ https://hal.science/hal-00571438}

Submitted on 1 Mar 2011

HAL is a multi-disciplinary open access archive for the deposit and dissemination of scientific research documents, whether they are published or not. The documents may come from teaching and research institutions in France or abroad, or from public or private research centers.
L'archive ouverte pluridisciplinaire HAL, est destinée au dépôt et à la diffusion de documents scientifiques de niveau recherche, publiés ou non, émanant des établissements d'enseignement et de recherche français ou étrangers, des laboratoires publics ou privés. 
health: An Interdisciplinary Journal for the Social Study of Health,

Illness and Medicine

Copyright () 2007 SAGE Publications

(Los Angeles, London, New Delhi and Singapore)

DOI: $10.1177 / 1363459307080869$

\title{
'That's just the cesspool where they dump all the trash': exploring working class men's perceptions and experiences of social capital and health
}

Vol 11(4): 475-495

\author{
Alan Dolan \\ University of Warwick, $U K$
}

\begin{abstract}
This article explores issues relating to the concept of social capital which has been become an important explanation for inequalities in health. It is based on an analysis of in-depth interviews with working class men living in two contrasting socio-economic areas - one relatively disadvantaged and one advantaged. It highlights the role of different community contexts in the nature and extent of local social capital. In particular, it demonstrates how de-industrialization and economic change as well as material deprivation and a perceived dis-investment in local communities impacted on the men's levels of social capital. Analysis also shows the ways in which gender mediates the processes through which social capital is developed and accessed as a personal and social resource, and how the norms and values associated with working class masculinities appeared to preclude the men from building supportive health-enhancing relationships with others in their community. The prominence of social capital has focused attention on the subjective dimensions of community life as potential determinants of health. This article has, therefore, sought to contribute to this field by widening our understanding about the relationship between social capital, gender and health.
\end{abstract}

KEYWORDS gender; masculinity; men's health; social capital.

ADDRESS Alan Dolan, School of Health \& Social Studies, University of Warwick, Coventry, CV4 7AL, UK. [Tel: +44 02476 573850; fax: +44 02476 524415; e-mail: a.dolan@warwick.ac.uk]

\section{Introduction}

This article is based on qualitative research undertaken in north-east Coventry, UK. It explores issues relating to the concept of social capital, 
which in recent years has become a significant explanation for health inequalities (Muntaner and Lynch, 2002). Accordingly, researchers have been encouraged to examine the ways in which individuals are embedded in their social networks and communities and how these operate to influence health. However, while considerable progress is being made in research that explores the concept of social capital and health, a number of imperatives for further research have been identified. These include: the need for more research into the forms taken by social capital in various historical cultural and socio-economic contexts; greater understanding of the ways in which gender may mediate the processes through which social capital is created and used as a personal and social resource; and the need for more qualitative research that focuses directly upon lay understandings and experiences of social networks and community life and how these impact on health and illness.

This article explores these issues through in-depth interviews with working class men drawn from two contrasting areas. One is an area of high material deprivation and the other is more affluent in terms of factors such as housing, income and levels of employment, enabling comparisons to be drawn about the ways in which social capital is experienced by men in varying community contexts. In presenting its findings this article will concentrate on the participants' perceptions and experiences of their social networks and communities and their views on how these affect their health.

I start by briefly reviewing the literature pertaining to social capital and health. The literature concerning masculinity and men's health will also be briefly examined, identifying the main issues relevant to this article. I then introduce the study design before moving on to present the empirical findings. The article concludes by discussing the findings and from this makes some suggestions that may inform future research into the links between social capital, gender and health.

\section{Social capital: what is it and why does it matter for health?}

In Britain, since the 1980 publication of the Black Report on health inequalities (Townsend and Davidson, 1982), research on the variation in health status among people with different socio-economic status has intensified (see Acheson, 1998). A host of studies have highlighted how historical, social, political, economic and contextual factors play an important role in accounting for the health outcomes of individuals and communities (see Marmot and Wilkinson, 1999). Central to these developments has been the growing interest in the concept of social capital; 'as having potential to articulate the relationship between health and its broader social determinants' (Swann and Morgan, 2002: 4).

While social capital is a relatively recent addition to the field of health inequalities the concept is not a new one. The central elements of what is generally viewed as social capital, namely 'a resource produced and accessed 


\section{Dolan: Working Class Men's Perceptions of Social Capital}

through co-operative social networks' (Cattell, 2004: 946), has its theoretical roots in anthropology, economics and classical sociology; Durkheim's (1933 [1893]) seminal work on suicide in the 19th century, for example, illustrated how social integration and cohesion influenced mortality.

While the concept of social capital has been defined by a number of theorists (Portes, 1998), the notion that has underpinned most research, at least within the fields of social epidemiology and public health, can be traced to work by Robert Putnam (1995) on civic engagement and the impact this had on economic and political life, both in Italy and the United States. Here, social capital is defined in terms of both social networks (high levels of participation in community groups and activities) and norms (high levels of trust and reciprocity among community members) 'that facilitate co-ordination and cooperation for mutual benefit' (Putnam, 1995: 67).

Putnam distinguishes two main types of social capital - 'bonding' and 'bridging'. Bonding social capital refers to the strong ties between members of a social network who see themselves as homogeneous; reinforcing specific reciprocity and mobilizing 'community spirit'. These networks help to engender trust, and to communicate and enforce norms of behaviour among group members. In contrast, bridging social capital refers to the links across different social groups in society that do not necessarily share similar social identities (i.e. weaker ties with individuals and groups outside of one's immediate or localized networks). This type of social capital is crucial for the success of civil society because it provides opportunities for participation and exchange and reinforces sentiments of trust within a society.

Accordingly, a set of key constructs (often used as indicators) of social capital have been identified; these include social relationships, shared norms, trust, reciprocity, formal and informal social networks, activity in local groups and civic engagement (Campbell, 1999). Societies where social capital is abundant are characterized by people's sense of community, their sense of belonging to a neighbourhood, their caring about the people who live there and their belief that people who live there care about them, which encourage community involvement.

Putnam (2000) made the case for the beneficial health effects of social capital by drawing on previous studies of social support, which found social networks, social activities and participation in organizations to be healthenhancing (see, for example, Berkman and Breslaw, 1983; Cohen and Syme, 1985). More recently, research on the health effects of social capital per se has highlighted the apparent benefits associated with trust and norms of reciprocity within social networks (Kawachi and Berkman, 2000).

However, the social capital and health link is not without its critics. Peace and Davey Smith, for instance, describe much of the evidence concerning social capital and health as 'less than compelling' (2003: 125). They point to work by Lynch and colleagues (2000) that could only find relatively weak and inconsistent associations between levels of social capital and mortality. Moreover, they argue even where associations have been observed between 
measures of social capital and health, it is by no means established that this association is causal. In addition, researchers such as Cattell (2001) have also highlighted limitations in our understanding of the mechanisms linking social capital to health. She notes the failure of most research to address which dimensions of social capital - bonding or bridging - are most effective in protecting health. Similarly, Campbell (1999) believes that certain aspects of social capital, especially trust and reciprocity, are more likely to be beneficial to health than other elements, such as community identity, but these differences in health-enhancing effects have never been clearly ascertained.

In their recent commentary, Whitehead and Diderichsen suggest the main reason for ambiguity in the relationship between social capital and health lies with its flawed conceptualization - 'social capital means different things to different people' (2001: 165), which has resulted in a 'minefield' of conflicting empirical evidence. Disagreement exists, for example, about whether the benefit of social capital is a collective resource residing within communities or societies, or whether it is individual; associated with people and their networks. While most public health researchers believe it is the property of social groups or networks (e.g. Kawachi and Berkman, 2000), it is also viewed as the capacity of individuals to command scarce resources by virtue of their membership in groups or networks (e.g. Portes, 1998). Wide variation has also been found in the operationalization of the concept; measures range, for example, from civic engagement and perceptions of crime, to social mistrust and the structure of family and friendship ties (Boneham and Sixsmith, 2006). Thus, despite nearly two decades of conceptual and empirical work, definitive definitions and the means to measure social capital remain somewhat elusive and it is also unclear as to which characteristics of communities and societies affect health.

It is within this context that social capital has come to the fore as a prominent explanation for inequalities in health. Indeed, social policies to intervene within marginalized communities to improve levels of social capital have increasingly been portrayed as a means of reducing health inequalities (Muntaner et al., 2000; Peace and Davey Smith, 2003). However, here again, there is no consensus on the nature of how social capital might be related to differential health outcomes. One interpretation (Campbell, 1999) has suggested that levels of social capital in poorer communities may act as a buffer, protecting residents from the harsher effects of deprivation. Others (e.g. Wilkinson, 1996) have put forward the idea that income inequalities may disrupt social relations, norms and trust through individuals' perception of their relative position in the social hierarchy, thereby reducing community involvement. Alternatively, Lynch and colleagues (2000) argue that it is the lack of health-enhancing resources at an individual level in conjunction with deprived social resources and neglected infrastructure at the community level that play the major role in the decline of social capital and health. While this debate is ongoing, there is general concurrence 
that social capital remains a useful approach with the potential to help us understand how socio-economic factors may influence health, and, as such, warrants further investigation.

The aim of this article is to explore some of the issues raised in these current debates, via an examination of the ways in which two groups of men living in two contrasting socio-economic areas are embedded in their social networks and communities and how these operate to influence health. The design and focus of the study has been influenced by a relatively small but growing body of UK research, which has highlighted a number of imperatives for research into the links between social capital and health.

First, a number of authors have highlighted the need for more research into the forms taken by social capital in various contexts (e.g. Campbell, 1999; Popay, 2000; Cattell, 2001; Campbell and McLean, 2002; Boneham and Sixsmith, 2006). Together, they highlight how much research has tended to treat communities and people within them as homogeneous groups. As such, it has failed to provide an in-depth understanding of the local contingent mechanisms and conditions through which social capital may be generated in certain geographical contexts and not in others. In the light of this, they suggest that researchers should strive to understand the ways in which the collective elements of community life are grounded in the mediating contexts and compositions of particular places. Popay, for example, conceptualizes social capital as a 'dynamic process', involving close linkages between people and the communities in which they live, which has 'a past as well as a present and future' (2000: 401). Meanwhile, Cattell (2001) has demonstrated how neighbourhood characteristics, such as area history, work opportunities, local resources and opportunities for community participation, influenced the formation of social networks and the forms of social capital created, in turn affecting health. Thus, in this study, two contrasting socioeconomic areas were chosen as the sites of investigation on the basis they would provide greater opportunities to explore the role of different community contexts in the nature and extent of local social capital.

Second, commentators have also suggested that more work is required to improve our understanding of the role of gender (as well as age and ethnicity) in the construction and development of social capital (Sixsmith and Boneham, 2002; Boneham and Sixsmith, 2006). This argument focuses on the fact that, despite evidence which suggests men and women may create, maintain and develop social capital in different ways (e.g. women appear to be more active than men in individual and community networks) (Davidson et al., 2003), the gendered reality of community life has received relatively little research attention. One important exception to this has been the recent study by Sixsmith and Boneham (2002), which first explored social capital as a gendered concept from the perspective of men and masculinities.

Historically, studies of gender and health have largely focused on women's experiences (Doyal, 1995). More recently, however, research has begun to draw attention to men's health; men's mortality rates are higher than that 
of women in every age group, for example (Acheson, 1998). Much of this attention, however, centres on men's greater propensity to adopt health damaging behaviours, such as smoking, drinking, violence and fast driving, to account for men's poorer health outcomes (see, for example, the Department of Health's (1993) review of men's health). Implicit in this perspective is a view that many men simply abdicate personal responsibility for health. Sociologists, in contrast, have concentrated on the linkages between dominant expressions of masculinity and male health (Doyal, 2000; Watson, 2000). This illustrates how living up to the norms of masculinity, which encourage emotional and physical strength and reject weakness or vulnerability, may cause men to define certain 'risky' behaviours as essentially masculine attributes.

In relation to social capital, Sixsmith and Boneham (2002) found that access to health-enhancing social networks for the men in their study could also be constrained by dominant aspects of masculinity, for example stoicism and independence, which prevented men seeking support. Moreover, these men's access to community resources could be curtailed by the perceived 'feminization' of community spaces. Thus, one drawback to making social capital a major focus of social policy to reduce health inequalities is the potential danger of excluding men. However, they call for further research to unpack the complexity of relationships between social capital, health and gender. Thus, my study sought to explore the ways in which working class men develop and maintain social relationships and how this may be shaped by the different community contexts in which they live.

Finally, a number of authors have highlighted the need for more qualitative research to consider better the subjective, experiential dimensions of social capital (Swann and Morgan, 2002; Boneham and Sixsmith, 2006). It is suggested that the predominately quantitative nature of much previous social capital research often masks the complexity of meanings that people themselves attach to their experiences of community relationships (Lynch et al., 2000). Popay (2000), for example, argues that we need to move beyond the debates about 'macro statistical relations', which may attempt to take account of such relationships, but at best only access people's subjective feelings superficially, divorced from their life context. Individual experiences and perspectives have been heralded as potentially providing invaluable insights into the specific processes and mechanisms through which the potential health-enhancing properties of social capital might operate (Boneham and Sixsmith, 2006). Thus, this study chose a qualitative exploration of men's lived experiences as a means to reveal the complexities of the relationship between social capital, community context, health and gender.

\section{Methodology}

The analysis presented in this article arose from research that aimed to explore how two groups of working class men living in contrasting communities 


\section{Dolan: Working Class Men's Perceptions of Social Capital}

understand and experience social ties and community participation and how these are perceived to impact on their health. The study took place in two wards - one relatively disadvantaged and one advantaged - in the city of Coventry located in the West Midlands, UK. A comparative approach based on two separate localities was adopted to enable distinctions to be drawn about how social capital is generated, maintained and accessed in the context of varying social, economic and cultural circumstances. This study design also allows comparisons to be made of men's lived experiences within as well as between the two areas. Working class wards were chosen as the sites of investigation on the basis that this is where 'the forces which create health inequalities are most profound' (Forbes and Wainwright, 2001: 813). Analysis of small area data from the 1991 Census was used to categorize wards as either 'affluent' or 'non-affluent' according to: levels of employment in social classes IIIM, IV and $\mathrm{V}$; levels of unemployment; housing tenure; household access to own transport; and levels of overcrowding. As a result of these processes, two wards were selected for investigation: St Mary's (affluent) and Hibbs (non-affluent).

These wards, which are geographically adjacent, differ in the profile of residents in terms of poverty, deprivation and unemployment and in terms of their potential for the creation of social capital. The 'affluent' area has traditionally been home to the city's relatively well-paid and 'well-protected' skilled manual working class (Mizen, 1995). It is characterized by large well-built suburban private estates and high-status council estates with high rents and purpose-built community facilities. It is one of the areas of the city in which the manufacturing and car industries were spatially concentrated, and therefore where the effects of the decline of these industries that occurred in the 1980s and early 1990s were socially concentrated. Although the area has shown signs of recovery, the legacy has been changes in local patterns of employment and income believed to be important for levels of social capital (see Wilkinson, 1996). Although many weathered the storm of industrial decline, substantial numbers of residents, including many skilled manual workers, experienced unemployment, job insecurity and a relative decline in income and status.

In contrast, the 'non-affluent' area is an area of economic and social disadvantage with high rates of unemployment, high proportions of unskilled and semi-skilled manual workers and has suffered historically from a stigmatized reputation linked to deprivation and high crime levels. Official statistics in the mid-1990s ranked it as among the bottom 10 per cent of the most deprived wards in the UK (Coventry City Council, 1996). The area is dominated by two of the most disadvantaged council estates in the city: Wood Green and Manor Croft. These were built as part of Coventry's large-scale 'peripheral' public housing schemes in the mid-1950s that replaced many of the city's inner-city council homes destroyed or irreparably damaged by bombing. Constructed of 'no fines' solid concrete slabs, these homes are renowned for being expensive to heat and prone to dampness (Geddes, 1997). The badly designed and poorly maintained housing, high 
rates of crime and anti-social behaviour, and poor reputation have led to an increase in population turnover and undermined community life. Yet, the area has a history of sustained community development activity and provides opportunities for involvement in community-based projects.

A comparative approach based on two separate localities was adopted to explore contextual effects with in-depth semi-structured interviews employed to explore individual experiences and perspectives. The data used in this article draw upon interviews conducted with 22 men (11 from each of the study areas) most of whom were recruited through a number of key contacts working in community and public settings and via informal social networks. Recruitment sites included an employment development project, a family centre, a community advice centre, a local college and a social club. The process of recruiting informants was a lengthy one. Posters and leaflets were displayed at each of these sites and key contacts explained the project to men they had dealings with. Those expressing an interest in the research and meeting the eligibility criteria (resident within the respective ward boundary) were introduced to the researcher by the contact. The researcher also spent time within different recruitment settings, approaching and speaking to men and women about the research, which recruited three men to the study (one directly and two via their partners). Two men contacted the researcher independently, having seen posters promoting the study. Every effort was made to reflect the demographic make-up of the areas and to include the less confident and socially excluded as well as those better known within their communities. All interviewees described themselves as white and heterosexual, which limits generalizability of the data.

The men who took part in this study ranged in age between 21 and 62, average age 40. All but four lived with a wife/partner (two of the men had divorced and lived alone, one lived with his parents and one was a lone parent). Of this sample, thirteen men had children living with them and five had adult children living away from home. In the affluent area, all of the men owned their own homes. Of this group, seven had, in the words of one, "come off-track', experiencing periods of layoffs, redundancy and unemployment. In some cases, employment had been found relatively quickly; for others, periods of short-term employment followed by more redundancies had become commonplace. In the 'non-affluent' area, all of the men lived in rented accommodation and four had been unemployed for over four years.

The men were each interviewed on two separate occasions. The decision to interview the men twice was predominantly influenced by initial concerns about building relationships and trust with these men. Some previous studies (e.g. Cornwell, 1986) had found men, particularly lower class men, as more likely to have difficulty talking about their life and health; linked to wider cultural prescriptions of working class masculinity. Repeat interviews were seen as providing greater opportunity to build relationships and allow access to more in-depth perceptions and experiences than might have be available through a one-off interview. On average, each interview lasted 
between one and a half and two hours and was carried out at a time and place of the participants' choosing, with the majority taking place in the men's homes. Interviews were informal and conversational, and men were encouraged, as much as possible, to dictate the course of the interview and to follow their interest in the topics I proposed to them. The part of the interview schedule that informed this article focused on the men's subjective experience of 'community', including levels of trust and neighbourliness, civic engagement in local community organizations, community networks and social relationships. Health was explored from a perspective that encompasses physical and psychological 'well-being' (Bowling, 1991) and relied on self-reported health status and common-sense understandings.

All of the interviews were recorded, fully transcribed and were manually coded and analysed. Coding and analysis was undertaken throughout the period of data collection so that findings of early fieldwork informed the focus of later data collection. Transcripts were coded by assigning labels to segments of the text and using these to describe them. Analysis of the data focused on the key themes emerging from the transcripts and was concerned to examine similarities and differences between men when talking about social networks, community participation and their views on how these affect their health. Confidentiality has been protected by using pseudonyms and changing local place names that could lead to the identification of participants.

\section{Findings}

\section{Men's perceptions of social capital in two contrasting socio-economic areas}

This section provides a brief picture of community life in the two contrasting areas, drawing on the men's perceptions of local identity, trust, reciprocal help and support and civic engagement - which constitute the main criteria for social capital (Campbell, 1999). The section begins by examining the perceptions of the men in the affluent area.

The men in the affluent area tended to describe it in favourable terms. Most felt part of the community, and described it as a relatively safe place to live with good supportive networks between neighbours. The following is characteristic of the affection and warmth men felt about the area:

I love it here. I wouldn't move if I won the lottery. ... We've been here thirty-four years. ... There's a relationship with most people along here. ... We all know if somebody's ill. ... We all do what we can to help. (Arthur 62, affluent area)

However, their sense of trust and respect did not automatically extend beyond their known neighbours to encompass relationships with everyone living on a particular estate. Likewise, while they contributed to a sense of community well-being by looking out informally for each other, their friendship networks did not necessarily include their neighbours: 
I have got good neighbours, but I wouldn't go to the extent that they were friends.

Most of my personal friends tend to live out of this area. ... I'm not somebody who is in and out of somebody's house. ... I'm not somebody who would be knocking on the door every few minutes. (Tom 41, affluent area)

The majority of the men in the affluent area did not join formal community activities or organizations; tending to prioritize work and family commitments or report little knowledge of such opportunities. Occasions when they had become involved were virtually always related to Neighbourhood Watch schemes; set up in response to specific incidents of crime and which were generally short-lived:

We'd had a spate of burglaries. ... So we started a Neighbourhood Watch. ... I was the secretary. But it's very difficult to keep going.... At first people are really interested and they're finding out what it can do for them ... then it just became a gossiping shop. (Lenny 57, affluent area)

However, although they were not involved in formal community activities, men did describe how they would sometimes employ their local social networks in an ad hoc fashion to deal with perceived threats to their quality of life. Patrick, for example, gave a graphic account of local men acting on information about newcomers to the area:

A new family moved in and all of a sudden houses were getting burgled. The police wouldn't do anything so all the guys sort of clubbed in. We were hiding in cars, in back gardens and kept watch and got them.... Well we didn't actually get them. ... My neighbour has got two Rotweillers and he just let them loose.... We couldn't have gone up in front of a jury, but they moved out a few days later [laughs]. (Patrick 37, affluent area)

Patrick's account is illustrative of likeminded men coming together to be proactive in the face of perceived criminal activity and what was defined as an ineffective response by the police. However, while such action appeared beneficial for the men involved, strengthening their community relationships and giving them a sense of defending their localities against forces of decline, it could be harmful to others. Thus, while on the one hand collective action could support trust and the mitigation of community problems it could simultaneously generate perverse forms of social capital, such as vigilante crime and other extra-judicial forms of local 'justice' (see, for example, Portes, 1998).

Some men in the affluent area also made reference to a perceived decline in social capital. Lenny, for example, who had lived in the area for over 20 years, felt people had become more wary of helping others. He reflected on how people had failed to come to his aid when he had fallen while shopping, which he perceived was people anticipating the worst case scenario and judging him to be personally responsible for his predicament:

I fell and broke my jaw. ... People were walking around me thinking I was drunk. ... I couldn't believe it ... no one stopped to help. People were walking around 


\section{Dolan: Working Class Men's Perceptions of Social Capital}

me thinking I was drunk ... at nine o'clock in the morning! (Lenny 57, affluent area)

Here, perceived changes in the composition of local residents were believed to have damaged their sense of common social identity with other local residents, which they linked to declining levels of neighbourliness. One example of such change related to a perceived influx of families viewed to be more affluent in comparison to the longer-term inhabitants, which had resulted in increasing unpredictability and anonymity among residents. Tom, for example, believed he was judged in negative ways by higher earners in his neighbourhood, which militated against a sense of trust:

It's becoming slightly more middle class. ... They see me and one or two others around here as different from them.... A building site worker sort of thing we're looked upon as letting the tone of the neighbourhood down a little bit. ... They would certainly be the type to report you if they knew you were working and signing on. (Tom 41, affluent area)

In a similar vein, Richard described what he perceived to be the egotistical or insensitive manner of some residents who were more fortunate; that is, those who had avoided redundancies, who he described as looking 'down their noses' at people like him who had lost their jobs. As a consequence, he felt strongly that people in his area had become less willing to help one another and talked frequently of the area being, 'not as decent as it was a few years ago'.

Importantly, all the men who perceived a decline in levels of social capital had experienced a personal downturn in incomes and standards of living - linked to redundancies and unemployment. In this instance, gender roles and the expectations that flow from this, may have informed these changes in community relationships. Without exception, the men's relationships with their families were portrayed primarily in financial terms (this is consistent with previous conceptual and empirical work; see, for example, Connell, 1995; Morgan, 1996); where 'good' husbands/fathers were identified as those who provided reasonable standards of living for their families, whether in work or not. Thus, their perceived inability to reach the same standard as other men might have caused them to retreat from community relationships. In some ways, this finding resonates with Wilkinson's (1996) thesis that income inequalities may disrupt social relations through individuals' perception of their relative position in the social hierarchy. However, it was the attitudes and behaviour they associated with people on higher incomes which was the main source of negative feelings, rather than higher incomes per se (for a detailed discussion of this, see Dolan, 2007).

The men living in the non-affluent area generally provided more negative accounts about their neighbourhoods and the people they lived among. For example, they described lower levels of trust and reciprocity, which they often linked to the perceived view that the local Council had implemented a policy of housing 'problem' families in the area. Phrases such as, 'a dumping 
ground for the kind of people who cause trouble' and 'the cesspool where they dump all the trash', were not uncommon when men described local neighbourhoods. Without the financial resources to enable them to leave, many felt trapped in an area renowned as having gained a bad reputation in the Coventry community as a whole:

Terrible! ... For instance. Not being allowed to have a rented television because you lived on Manor Croft. It was perfectly all right until you said Manor Croft and then you couldn't have it. ... You're a second class citizen. (Owen 52, nonaffluent area)

These men were more likely than those in the affluent area to experience problems with other people in their neighbourhoods. Past experiences of overt forms of anti-social and criminal behaviour - such as 'joy riding', vandalism, drugs and so forth - as well as large groups of young people, who intimidated residents, appeared frequently within these men's testimonies. Negative accounts were especially prevalent among the men living on or closest to the most deprived estates. For example, Owen, who had lived on the Manor Croft estate for over 20 years, described a dramatic transformation in community relations which had made him increasingly distrustful of others, including the police, who he perceived put 'ordinary' residents at risk:

It was a nice place. ... There was a community spirit ... but there is a difference between was and is. ... It's changed. I don't say it was a perfect environment. But this street when we moved in was quiet, with older people in it, a few children.... There's been just a gradual progression from what it was to what it is. ... It isn't as bad as it was but it became very very bad ... riots, murders, drugs, everything. Especially when you've got children and you know you can't rely on assistance. ... In fact you can rely on precisely the opposite that the police will not arrive until after it is finished. (Owen 52, non-affluent area)

Similarly, Matt described how he and his family had been the target of violence, robberies and intimidation from other residents on the Manor Croft estate. Matt's narrative is of isolation and of being overwhelmed by his fear of aggression that appeared as an ever present possibility in day-today interactions with other residents:

Housing officials don't have to take it home with them. We come home to ours every night. ... They say 'Oh it can't be that bad'.... They base it on how they live and how their neighbours live. Their neighbours look out for them. It's the exact opposite here. (Matt 33, non-affluent area)

Alongside and linked to this, virtually all of the men in the non-affluent area described how physical violence or the threat of violence was often a means by which difficulties between residents were resolved. Owen, quoted previously, for example, described how he had fought with neighbours who had sworn at him in front of his family. At the very least, one had to present oneself as confident and threatening: 


\section{Dolan: Working Class Men's Perceptions of Social Capital}

Sometimes you just have to. ... I go out there and I face up to them.... Then they will say 'OK, he's sound'. They'll leave you alone. ... If you stand up, you get respect ... if you don't ... they can make your life hell. (Bob 39, non-affluent area)

However, this component of local social capital was not accessible to all men. Matt, for example, quoted earlier, expressed a strong desire to stand up to those who targeted him and his family, but was not, in his words, 'a fighter', which contributed to his sense of vulnerability and precluded him building relationships with other men.

Importantly, a small number of men living in the non-affluent area presented a different and somewhat more positive picture of community life. For example, Bob, who had lived on the Wood Green estate for most of his life, felt a strong sense of affinity with other people living there, which he attributed to his intimate knowledge of what he referred to as 'the rules of the estate'. Importantly, he described how people gained the trust and respect of others by not informing the police of certain activities (for example not reporting people receiving stolen property or selling drugs, 'if you see anything, you say nothing'). He believed it was inevitable that people would use criminal behaviour as a means of attaining incomes when traditional avenues were perceived not to be available:

People get so frustrated. You can understand it in a way.... Especially the young people. Once they leave school they can't get work ... they don't want training schemes so they don't get any money at all.... You start finding them drifting on to the street ... and they start with the violence ... the robberies.... Then we've got the pirates with the drugs. 'If you sell this you will earn $£ 50$ '... Too right they are going to do it. ... People feel they have no choice. (Bob 39, non-affluent area)

He characterized such behaviour in terms of 'natural survival instincts'; people attempting to gain an advantage over others in conditions of severe material hardship, albeit with a nasty edge. For that reason, he believed local community initiatives, such as those designed to reduce drug-related crime, failed to take account of the role drugs and other illegal activities played in helping residents survive in such circumstances:

Like when they come in and say, 'Right we're going to clear you of drugs'. OK. That's great. But we say what are you going to replace it with? If you take something away, you have to replace it with something else. Work isn't here, so you can't replace it with work. (Bob 39, non-affluent area)

Bob had previously worked as a volunteer within his community but had become extremely disillusioned with community activists who he described as 'simply looking for medals'; that is, they dominated discussions and media headlines, but failed to understand the problems facing the area or improve links with employers and other groups outside the area. For example, he pointed out how regeneration schemes designed to enhance social capital did not overcome the lack of jobs and material resources that underlie 
his and other residents' sense of marginalization and alienation from wider society:

Money has been put in but it doesn't solve the problem. ... Patching up the place

... building community centres ... isn't giving people a sense that they are needed

... that they are needed in life. ... Employers have had their opportunity to pick me for the last 20 odd years and they haven't. ... They've never given me the opportunity to show them what I can do. (Bob 39, non-affluent area)

Thus, the findings from men in the non-affluent area appear to resonate with a 'neo-materialist' interpretation of social capital put forward by Lynch et al. (2000); that is, unemployment and low incomes together with the perceived dis-investment in their communities combined to reduce 'bonding' capital between residents. Moreover, these men also appeared unable to develop the sorts of relationships in which 'bridging' capital could feature. Disdainful treatment at the hands of others as well as blocked employment opportunities were familiar experiences for many of these men, which left them feeling frustrated and angry that society did not care about them.

\section{Working class masculinities and men's social networks}

It was evident that normative aspects of working class masculinity relating to independence, self-reliance and emotional strength, could constrain men's interactions with their neighbours and friends, regardless of their particular locality. Asking for help with practical problems, for example, was often associated with negative, undesirable images of masculinity:

I wanted to change the light on the stairs ... I haven't got a ladder. I am not going to go next door and ask the bloke if I can borrow his ladder. ... Because I don't want to look like I can't do it, like I haven't got a ladder. (Lee 34, affluent area)

There were many other examples where respondents shunned help in order to maintain traditional masculine definitions. Implicit in their accounts was distrust in other men not to ridicule them for their perceived limitations as men. The following quote from Marcus, concerning his next-door neighbour, illustrates how men's desire to maintain 'face' was used to explain their reluctance to seek help from other men:

He's like Mr DIY and does everything, he does his bit on the car, builds himself a patio. So I don't ask him [for help] because I feel inadequate. ... I should know about cars and how to change a washer on a tap. (Marcus 32, non-affluent area)

Not unsurprisingly, these men also defined asking for help with emotional problems as a sign of weakness or failure and, therefore, tended to keep their emotional needs hidden and rarely called on their social networks for personal support. One of the most striking features of this aspect of the men's narratives was the way many used emotional silence to maintain male identities, drawing on the perceived negative repercussions 


\section{Dolan: Working Class Men's Perceptions of Social Capital}

of disclosure to explain their reasoning. Phrases such as, 'I don't feel safe ... I don't feel anybody is non-judgmental' or 'I've got nobody in my life I can really trust' were common reasons for their unwillingness to discuss inner feelings. The following extract clearly illustrates their reticence around disclosure of emotional needs:

I haven't got a close friend that I could go to and say 'God I feel down'. I haven't got any friends that I could talk to about real stuff like that.... You don't want to make somebody fed up with hearing about you. ... I think ideally if I could have four or five friends on different subjects. They would never make the connection between one part and the other. I would feel a lot safer. (Marcus 32, non-affluent area)

Importantly, the men's theories about their own social networks tended to revolve around a consensus that women's relationships were more extensive, meaningful and beneficial, whereas men's relationships were defined as more instrumental and in many ways unsatisfying:

It seems to be a topic of conversation for women how they feel about themselves and their problems and that and it's not really how men talk. It's just taken for granted that you're OK. Men don't talk about feeling stressed and what that does to them.... We tend to keep away from stuff like that.... Maybe other men are different. Certainly the one's I know aren't. Unless they wait for me to go and open up to each other [laughs]. (Lee 34, affluent area)

In this quotation Lee is also pointing to another prominent theme running through these narratives - men's tendency to distance themselves from each other by concentrating on subjects and activities that were external to themselves. The following extract provides a common exemplar of the manner in which men concealed their emotional needs from friends and acquaintances:

Not even in our own company in the pub. ... We never talk about what we really want to talk about. ... We just will not let that barrier go. So we talk about something completely different ... football and sport, politics ... have a few jars and get a little bit tipsy and then off home. (Bob 39, non-affluent area)

These findings clearly resonate with those of Sixsmith and Boneham (2002) who found factors relating to gender could constrain men's social networks. However, importantly, this study has been able to provide further insights into the complex relationship between social capital and masculinity. It has shown how these men held firmly to notions of traditional working class masculinity, which restricted their ability to develop or access important aspects of social capital, regardless of their socio-economic circumstances or the extent to which they appeared to be embedded within their community setting. In other words, men in the affluent area who appeared to have reasonably strong bonding ties with neighbours could be as inhibited to ask for certain types of support as those men in the non-affluent area who appeared to have far weaker neighbourhood ties. 


\section{Working class masculinities, social capital and men's health}

The social constructions of masculinity that influenced these men's ability to access social capital also appeared to be counter-productive to their health. In the previous extract, for example, Bob hinted at how respondents could resort to behaviours considered more appropriate outlets for masculine expression to relieve stress (see also Eisler and Blalock, 1991). These behaviours included excessive smoking and drinking, as well as drug use and other potentially dangerous activities such as high-speed and reckless driving. The following comments illustrate how the aim was often to help men relax and keep their minds away from their problems:

I think a lot of men don't feel that they can talk about how they feel. There is other ways of doing it like smoking, drinking, driving at 150 miles per hour.... [Later in the interview] I used to drink before going to work. ... It was what I needed because I could not cope. ... I think it's the fact that you see yourself in a certain way and so you can't let others see that you're weak in some way that you need help and that you need advice or something like that. (Marcus 32, nonaffluent area)

In the case of Bob, who lived with his wife and four children in severe hardship, it appeared that the masculine characteristics relating to independence and self-sufficiency had left him alone with his problems and unable to ask for help until this had escalated to the point of him attempting suicide. In talking about this episode he continually used the analogy of 'filling a storage cupboard' to illustrate the process of concealing his emotional distress from those around him:

I took an overdose. I wanted to kill myself. ... Sometimes you feel so on your own and nobody really knows you and nobody really understands you. Nobody really knows what it's like. ... [Later in the interview] It just piled up on me. ... I'd been going round with this piling up for months.... All you're doing is just storing things up. Storing, storing. You know your store cupboard can only take so much and then all of a sudden it will explode. (Bob 39, non-affluent area)

Importantly, respondents often perceived women's apparent openness around their problems and concerns as health enhancing. Patrick, for example, believed that men's tendency not to talk about their problems was the main reason 'why men get heart attacks and women don't':

Us blokes we try to be all macho and try to bottle it up and try to sort it out ourselves. ... It gets built up and built up and built up and at the end it's going to find us out. (Patrick 37, affluent area)

In the context of what was widely perceived to be strong social pressure for men to maintain control and not show vulnerability, none of these men described talking about health matters with male friends, neighbours or colleagues (see Sixsmith and Boneham, 2002). As such, they appeared to have limited access to the 'informational potential' form of social capital, that could otherwise come from men in similar circumstances. The follow- 


\section{Dolan: Working Class Men's Perceptions of Social Capital}

ing quotation illustrates how men who did attempt to discuss health issues could be viewed in negative terms and were open to ridicule. On this latter point, Lee was one of several respondents who used pejorative terms, such as 'hypochondriac', 'sissy', 'wimp' and 'Nancy', to describe men perceived to have transgressed this masculine norm:

I know somebody who's like that ... people feel he's a hypochondriac type ... they take the micky out of him. ... It's just that image isn't it? 'You're a Nancy'. ... He's too open about it. (Lee 34, affluent area)

These men also illustrated how living in particular community contexts could impact on their health. The following quotation, for example, illustrates how neighbourhood behaviours could impact on men's emotional well-being, particularly when they perceived themselves unable to evoke change. Interestingly, although Simon's circumstances were similar to the case highlighted, he reported never having contemplated suicide:

Did you see that in the paper ... about the bloke sleeping in his car because of the noise off his neighbours? I could relate to that. ... Everybody has got a breaking point. ... He might not be able to stand up to them. It might make him commit suicide because he couldn't get round it any other way.... He hadn't got the thing to stand up to them or confront them. (Simon 25, affluent area)

However, the potential negative impact on health was most evident among those men living in adverse environments, where they felt little sense of connectedness to those around them. In the case of Matt, for example, who had been the victim of serious anti-social and criminal behaviour, the effects on his health were never far from the surface:

I can't sleep. Most nights I'm up until two or three. ... I had always taken a while to get to sleep but I never really had this feeling of paranoia ... and anxiousness. ... I think something is going to happen and I'm sitting on edge, waiting for it. ... Usually it's the thought that somebody's going to break in again, but it's not necessarily that. I've had fears of firebombs and general sort of vandalizing the property. ... You don't know whether to slit your throat, throw a brick, hit the kids or what. ... I have lost that happy go lucky element that was me for so long. (Matt 33, non-affluent area)

Similarly, Sean commented on how his health had been affected when living on the Wood Green estate:

It does affect you. ... Your stomach gets a bit dicky ... you don't feel brilliant. You're on edge all the time. ... You just don't want to go home because you don't know what you're going to find there. (Sean 27, non-affluent area)

\section{Conclusion}

The emergence of the concept of social capital has focused attention on the subjective and experiential dimensions of community relationships as potential determinants of health and illness. Accordingly, a growing body 
of UK research has begun to inform our understanding of how individuals and groups are connected in particular neighbourhoods. This study has attempted to make a specific contribution to this field through a qualitative exploration of how working class men living in relatively advantaged and disadvantaged areas perceive community life and social networks and how they theorize the way these impact on their health.

These findings have demonstrated how neighbourhood characteristics, combined with aspects of working class masculinity, influenced the forms and availability of social capital. In the affluent area, for example, men generally described how social capital was created and maintained in bonding ties within what had been relatively homogeneous neighbourhoods. However, a contemporary contextual effect on the degree of solidarity was also apparent, linked to de-industrialization and economic change. The accounts of men who had experienced redundancies and lay-offs illustrate their perception of how a general disposition of goodwill towards others had given way to one of suspicion and distrust, characterized by growing inequalities and recognition that social relationships had become more hierarchical and unsympathetic. In these cases, it appeared a relative decline in incomes and status impacted on social capital via the damage to their sense of identity and purpose as 'proper' working class men. Some of these men, who had viewed themselves as successful and valued members of their community, now believed they were perceived as inadequate or failures because they did not maintain better paid employment and standards of living. Thus, they perceived their sense of position in their local communities to be declining, leaving them feeling increasingly devalued and isolated within what they had previously perceived to be supportive communities. This resulted in feelings of hostility as well as rejection and injustice on the part of these men, which dented community relationships.

In the non-affluent area, long-term unemployment and poor material circumstances, together with the perceived local policy of decanting the most troublesome of families into the area, were repeatedly cited in relation to high levels of aggression, anti-social behaviour and crime. It was clear the perceived lack of trust and tolerance were grounded in the reality of these men's lives, borne out of the fear of violence that appeared to lurk as an ever-present possibility in day-to-day interactions with those around them. Linked to this, it was apparent that key sources of social capital - respect, integration and solidarity - could be intimately linked to men's ability to engender distinct features of traditional working class masculinity, namely toughness, dominance and the willingness to resort to violence to resolve interpersonal conflicts. In recent years, the notion that gender is partly structural and partly performatory has become a popular theme in discussions about men and masculinities. Accordingly, a number of commentators (see especially Messerschmidt, 1993) have sought to highlight the ways in which men 'do masculinity'; being violent, engaging in risk taking and so forth. Thus, it appeared that some men gained respect and built relationships 
with other men through aggression or at least presenting the demeanour of a 'tough guy'. Though we must be careful of placing too much emphasis on minority behaviour, none the less, their ability to demonstrate personal toughness appeared to bind some men within their communities while simultaneously excluding other men. The result was considerable diversity in the men's lived experience within their neighbourhood and in the way they responded to what appear to be broadly similar, albeit severe and demanding, circumstances.

It is also clear that these men perceived themselves to be embedded in their local communities and networks to different degrees and in different ways to women (see Sixsmith and Boneham, 2002). The men in this study were unanimous in their view that women were better social networkers than men and as a result could use and benefit more from the practical and emotional support on offer in their community. Whereas, for these men at least, the strong norms and values they associated with working class masculinities, such as self-sufficiency and self-control, made it difficult for them to ask people around them for help or advice, regardless of their personal circumstances or community location. Thus, they would conceal or disguise their practical problems or emotional concerns rather than take the risk of discovering other people's reaction because it was too threatening to their identities as men. Therefore, although many of these men acknowledged that the expression of how one was feeling was potentially beneficial to physical and emotional health, the prescriptive definitions of working class masculinity appeared to preclude them from building supportive healthenhancing relationships with others in their community.

This research, while limited in size, has sought to capture some of the complexity attached to working class men's attitudes and experiences concerning social capital and health. However, the need remains to explore further the gendered notion of social capital and its relationship with health in relation to other groups of men. Thus, future research may wish to pursue the experiences of men further up the social ladder, as well as the experiences of black and minority ethnic group men. Only by obtaining personal accounts from different social groups of men, right across the social spectrum, will a fuller understanding of the meanings and processes involved in building and maintaining social capital within different communities become visible.

\section{References}

Acheson, D. (1998). Independent inquiry into inequalities in health. London: The Stationery Office.

Berkman, L. and Breslaw, L. (1983). Health and ways of living: The Alameda County Study. Oxford: Oxford University Press.

Boneham, M. and Sixsmith, J. (2006). The voices of older women in a disadvantaged community: Issues of health and social capital. Social Science and Medicine, 62(2), 269-79. 
health: 11(4)

Bowling, A. (1991). Measuring health: A review of quality of life measurement scales. New York: Open University Press.

Campbell, C. (1999). Social capital and health. London: Health Education Authority.

Campbell, C. and McLean, C. (2002). Ethnic identity, social capital and health inequalities: Factors shaping African-Caribbean participation in local community networks in the UK. Social Science and Medicine, 55(4), 643-57.

Cattell, V. (2001). Poor people, poor places, and poor health: The mediating role of social networks and social capital. Social Science and Medicine, 52(10), 1501-16.

Cattell, V. (2004). Having a laugh and mucking in together: Using social capital to explore dynamics between structure and agency in the context of declining and regenerated neighbourhoods. Sociology, 38(5), 945-63.

Cohen, S. and Syme, S. (1985). Social support and health. Orlando, FL: Academic Press.

Connell, R.W. (1995). Masculinities. Cambridge: Polity Press.

Cornwell, J. (1986). Hard earned lives: Accounts of health and illness from East London. London: Tavistock.

Coventry City Council. (1996). Coventry and Warwickshire economic review. Issue 9. Coventry: Coventry City Council.

Davidson, K., Daley, T. and Arber, A. (2003). Older men, social integration and organisational activities. Social Policy and Society, 22(2), 81-9.

Department of Health. (1993). On the state of the public health. London: HMSO.

Dolan, A. (2007). 'Good luck to them if they can get it': Exploring working class men's understandings and experiences of income inequality and material standards. Sociology of Health and Illness, 29(5), 1-19.

Doyal, L. (1995). What makes women sick: Gender and the political economy of health. London: Macmillian.

Doyal, L. (2000). Gender equity in health: Debates and dilemmas. Social Science and Medicine, 51(6), 931-9.

Durkheim, E. (1933 [1893]). Divisions of labour in society. New York: Free Press.

Eisler, R.M. and Blalock, J.A. (1991). Masculine gender role stress: Implications for the assessment of men. Clinical Psychology Review, 11, 45-60.

Forbes, A. and Wainwright, S.P. (2001). On the methodological, theoretical and philosophical context of health inequalities research: A critique. Social Science and Medicine, 53(6), 801-16.

Geddes, M. (1997). Partnership against poverty and exclusion. Bristol: The Policy Press.

Kawachi, I. and Berkman, L. (2000). Social cohesion, social capital and health. In L. Berkman and I. Kawachi (Eds.), Social epidemiology, pp. 174-90. New York: Oxford University Press.

Lynch, J., Davey Smith, G., Kaplan, A. and House, S. (2000). Income inequality and mortality: Importance to health of individual income, psychosocial environment, or material conditions. British Medical Journal, 320, 1200-4.

Marmot, M. and Wilkinson, R.G. (1999). Social determinants of health. Oxford: Oxford University Press.

Messerschmidt, J. (1993). Masculinities and crime: Critique and re-conceptualisation of theory. New York: Rowan \& Littlefield.

Mizen, P. (1995). The state, young people and youth training. London: Mansell.

Morgan, D. (1996). Family connections. Cambridge: Polity Press. 


\section{Dolan: Working Class Men's Perceptions of Social Capital}

Muntaner, C. and Lynch, J. (2002). Social capital, class, gender and race conflict, and population health: An essay review of Bowling alone's implications for social epidemiology. International Journal of Epidemiology, 31(1), 261-7.

Muntaner, C., Lynch, J. and Davey Smith, G. (2000). Social capital and the third way in public health. Critical Public Health, 10(2), 107-24.

Peace, N. and Davey Smith, G. (2003). Is social capital the key to inequalities in health? American Journal of Public Health, 93(1), 122-9.

Popay, J. (2000). Social capital: The role of narrative and historical research. Journal of Epidemiology and Community Health, 54(6), 401.

Portes, A. (1998). Social capital: Its origins and applications in modern sociology. Annual Review of Sociology, 24, 1-24.

Putnam, R. (1995). Bowling alone: America's declining social capital. Journal of Democracy, 6(1), 65-78.

Putnam, R. (2000). Bowling alone. New York: Simon \& Schuster.

Sixsmith, J. and Boneham, M. (2002). Men and masculinities: Accounts of health and social capital. In C. Swann and A. Morgan (Eds.), Social capital for health: Insights from qualitative research, pp. 47-60. London: Health Development Agency.

Swann, C. and Morgan, A. (Eds.). (2002). Social capital for health: Insights from qualitative research. London: Health Development Agency.

Townsend, P. and Davidson, N. (1982). Inequalities in health: The Black Report. London: Penguin.

Watson, J. (2000). Male bodies: Health, culture and identity. Buckingham: Open University Press.

Whitehead, M. and Diderichsen, F. (2001). Social capital and health: Tip-toeing through the minefield of evidence. The Lancet, 358(9277), 165-6.

Wilkinson, R.G. (1996). Unhealthy societies: The afflictions of inequality. London: Routledge.

\section{Author biography}

A LAN DOLAN's areas of research interests include inequalities in health, men's health, poverty and smoking. His doctoral research is in the area of men's health and he has worked on a number of research studies concerned with varying aspects of men's lives and health. In addition, Dr Dolan has been a grant holder on projects that have explored fathers' knowledge and beliefs around smoking and new fathers' experiences around maternity services. 